\title{
Transient Thermomechanical Simulation of 7075 Aluminum Contraction around a $\mathrm{SiO}_{2}$ Microparticle
}

\author{
Pedro Alejandro Tamayo-Meza ${ }^{1, *}$, Miguel Ángel Cerro-Ramírez ${ }^{2}$, Emmanuel Alejandro Merchán-Cruz ${ }^{1}{ }^{\circledR}$, \\ Usiel Sandino Silva-Rivera ${ }^{3}$, Raúl Rivera-Blas ${ }^{1}\left[\right.$ and Luis Armando Flores-Herrera ${ }^{1, *(1)}$ \\ 1 Postgraduate Studies and Research Section, Instituto Politecnico Nacional, Higher School of Mechanical and \\ Electrical Engineering, U. Azcapotzalco, Av. Granjas 682, Mexico City 02250, Mexico; \\ eamerchan@ipn.mx (E.A.M.-C.); rriverab@ipn.mx (R.R.-B.) \\ 2 Mechatronics Engineering Department, Tecnológico de Estudios Superiores de Coacalco, Av. 16 de \\ Septiembre 54, Coacalco de Berriozábal 55700, Edo. de Mex., Mexico; miguel_cerro.ccai@tesco.edu.mx \\ 3 SEDENA, D.G.E.M., Escuela Militar de Ingenieros, Secc. of Industrial Engineering, Army and Air Force \\ University, Escuela Militar de Ingenieros, Av. Industria Militar 261, Naucalpan de Juarez 53960, Edo. de Mex., \\ Mexico; ussilvar@ing-mil.com \\ * Correspondence: ptamayom@ipn.mx (P.A.T.-M.); lafloresh@ipn.mx (L.A.F.-H.)
}

check for updates

Citation: Tamayo-Meza, P.A.; Cerro-Ramírez, M.Á.; Merchán-Cruz, E.A.; Silva-Rivera, U.S.; Rivera-Blas,

R.; Flores-Herrera, L.A. Transient

Thermomechanical Simulation of 7075 Aluminum Contraction around a $\mathrm{SiO}_{2}$ Microparticle. Materials 2021, 14, 134. https://doi.org/10.3390/ma 14010134

Received: 31 October 2020 Accepted: 25 December 2020 Published: 30 December 2020

Publisher's Note: MDPI stays neutral with regard to jurisdictional clai$\mathrm{ms}$ in published maps and institutional affiliations.

Copyright: (C) 2020 by the authors. Licensee MDPI, Basel, Switzerland. This article is an open access article distributed under the terms and conditions of the Creative Commons Attribution (CC BY) license (https:// creativecommons.org/licenses/by/ $4.0 /)$.

\begin{abstract}
One important challenge that faces the metallurgic industry turns around the constant increment in the mechanical resistance of certain finished products. Metallurgic advantages can be obtained from the inclusion of microparticles in metallic materials, but this inclusion involves complex challenges as the internal stress distribution can be modified. In this work, the simulation of a cooling sequence in 7075 aluminum with a $\mathrm{SiO}_{2}$ microparticle is presented. Two models of twodimensional (2D) type were constructed in ANSYS ${ }^{\circledR} 2019$ with circular and oval shape microparticles located inside the aluminum. Both models were subjected to the same thermomechanical transient analysis to compare the remaining stress distributions around the microparticles after the thermal load and to observe the effect of the geometrical shape. The results show remaining stresses increased in the oval model as a consequence of the geometrical shape modification. After applying a tension load in the analyzed specimens, shear stress concentrations were observed with a higher magnitude around the covertex of the oval shape. The results can be very useful for the creation of materials with controlled remnant stress located in specific or desired locations in the matrix.
\end{abstract}

Keywords: microparticle; stress state; plate defects; simultaneous cooling

\section{Introduction}

The size, shape, composition, and concentration of the non-metallic inclusions play a fundamental role in one of the main properties of the alloy, in this case, the viscosity. The presence of defects in metallic matrices can create cracks that propagate depending on their size, geometry, and orientation [1,2]. On the other hand, the presence of inclusions and microparticles creates stress concentration points that modify the mechanical behavior of the material, its resistance, and its machinability [3-6], especially when they are subjected to considerable temperature treatments [7-9].

Liquid metal foundries have a micro heterogeneous structure, in which three structural zones can be distinguished: (a) a zone with relatively stable solid formations, with a useful life of $\tau$ : $10^{-9}$ to $10^{-10} \mathrm{~s}$ and dimensions of 10-100 $\AA$; (b) a zone of active atoms, which are simultaneously part of the groups (clusters) and have greater energy and mobility; and finally, (c) a zone of free space volume, which includes the region of bond breaking between the groups and appears and disappears constantly in the process of thermal vibration of the clusters (groups).

Oxides, sulfides, pores, silicates, and nitrogen, in the form of non-metallic inclusions, sensitively affect the mechanical resistance of metals [10-15]. The non-metallic inclusions 
are potential stress concentrators and the source of crack incubation processes that can lead to a desired mechanical behavior if they are properly controlled. Oxide particles, such as $\mathrm{Al}_{2} \mathrm{MgO}_{4}, \mathrm{Al}_{2} \mathrm{O}_{3}, \mathrm{MgO}$, and $\mathrm{SiO}_{2}$, observed in aluminum alloys are extremely hard concerning the matrix and their treatment represent a complex technological challenge [16-22]. The addition of microparticles in metals, combined with proper thermomechanical treatment, can be used to increase the mechanical properties in a beneficial sense [23-32].

\section{Materials and Methods}

\subsection{Problem Description}

The study was carried out with consideration of the main characteristics of Al 7075 (Al-Zn-Mg-Cu type), together with Al 2024 (Al-Cu-Mg type). The pressing recrystallization temperature ranges between 300 and $350{ }^{\circ} \mathrm{C}$ and the non-pressing recrystallization temperature is between 420 and $450{ }^{\circ} \mathrm{C}$. The structural alteration of aluminum alloys is related to the modification of their chemical properties. In this phenomenon, the greatest influence is exerted by second phase intermetallic inclusions, which are precipitated from the melt and distributed along both the grain edges and the inter-dendritic zones. These particles can modify the general characteristics of the alloy as well as its resistance to fracture. Second phase inclusions, such as $\mathrm{Al}_{2} \mathrm{O}_{3}, \mathrm{CuAl}_{2}$, and others, create microcracks, the irregularly shaped particles that break near the matrix interface. Microcracks arising from the inclusions are transferred to the slip bands, which generate thin regions along the trajectory. By increasing the volumetric portion of these second phases, the relative elongation is reduced by approximately $5.1 \%$ to $2.9 \%$, that is, by 1.8 times. This effect is catastrophic when manufacturing mechanical implements, mechanical structures, or mechanisms in engineering [33-36].

The chemical composition of the alloy is a fundamental issue in the formation of the structure and the intermetallic inclusions. It is, therefore, very timely to now share the following case that we have developed for an alloy of the Al- $\mathrm{Zn}-\mathrm{Mg}-\mathrm{Cu}$ system [37]. This alloy was composed of $5.7 \%$ of $\mathrm{Zn}, 2.2-2.7 \%$ of $\mathrm{Mg}, 1.5-2.0 \%$ of $\mathrm{Cu}, 0.11-0.17 \%$ of $\mathrm{Zr}$, and an amount of Fe and $\mathrm{Si}<0.15 \%$. From this combination, we obtained a $\sigma_{0.2}=49.5 \mathrm{~kg} / \mathrm{mm}^{2}$, $K_{1 c}=123 \mathrm{~kg} / \mathrm{mm}^{3 / 2}$, and $K_{1 c}=95 \mathrm{~kg} / \mathrm{mm}^{3 / 2}$. Subsequently, we developed the following set of modifications in the chemical composition: $5.6 \%$ of $\mathrm{Zn}, 2.5 \%$ of $\mathrm{Mg}, 1.6 \mathrm{of} \mathrm{Cu}, 0.7 \%$ of $\mathrm{Fe}, 0.5 \mathrm{of} \mathrm{Si}$, and $0.2 \%$ of $\mathrm{Cr}$. From this combination, we obtained a $\sigma_{0.2}=40 \mathrm{~kg} / \mathrm{mm}^{2}$, $K_{1 c}=88 \mathrm{~kg} / \mathrm{mm}^{3 / 2}$, and $K_{1 c}=76 \mathrm{~kg} / \mathrm{mm}^{3 / 2}$. From these results, we deduced that the alloy in the Al-Zn-Mg-Cu system with a lower content of Fe and $\mathrm{Si}$, and that contained $\mathrm{Zr}$ instead of $\mathrm{Cr}$, presented better toughness and resistance to crack propagation caused during fatigue loads and higher resistance to corrosion with respect to the widely known 7075-T765.

In recent years, some authors have expressed concerns about the generality of the principle of orientation for boundary conditions. At the same time, electrochemical theories have made it possible to consider the influence of important factors, such as the electrical nature of the metal and the inclusion. The idea of an electrochemical approach towards the interaction of refractory, insoluble inclusions with liquid metal is based on a change in the level of the Fermi energy of two substances in close contact and the formation of an electrical double layer at the contact surface [38].

\subsection{Construction of the Geometry and Boundary Conditions}

Figure 1a shows a random distribution of microparticles (dots) within the matrix. This could be an idealized condition used to calculate a stress distribution across the material. However, the number of variables that can be presented in the real physical scenario is more complex. For example, as shown in Figure 1b, the microparticles could be located at the intersections of grains, or, as shown in Figure 1c, variable sizes and shapes of microparticles could create shorter or larger distances between each other, thus modifying the wear resistance or some other mechanical requirement [31,32]. Up to this point in our research, we have focused only on the analysis of a single microparticle and its stress 
distribution when subjected to a contraction process caused by changes in temperature. Microparticles can have different geometrical shapes and sizes; additionally, they can be distributed in the metallic matrix without a specific order.

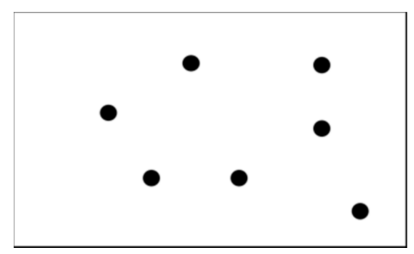

(a)

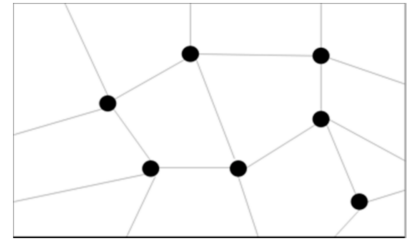

(b)

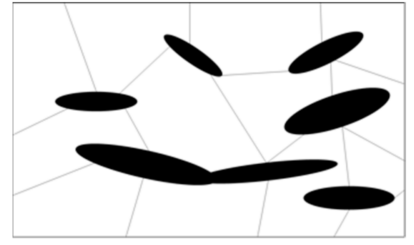

(c)

Figure 1. (a) Random distribution of the microparticles in the matrix, (b) location of the microparticles in boundary grains intersections, and (c) variability of microparticle size and shape.

To simplify a single scenario of this problem, we consider a circular microparticle with radius $r$ located inside a metallic matrix as shown in Table 1. Consider now, from an initial temperature, that both materials are in a cooling sequence. Assume that the matrix achieves an initial temperature $T_{i}$, reduced up to $T_{f}$, which can be room temperature for this example. Based on this concept, only two-dimensional (2D) models were constructed. They have a squared shape, are $1 \mathrm{~mm}$ in length, and are oriented in the $x, y$ plane. The second and third columns indicate the location of the loads for the Transient Thermal and Static analyses. Inside the square, a proposed circular shape microparticle with a $0.1 \mathrm{~mm}$ diameter was located for the first case. The circular microparticle has an equivalent area of $0.0314 \mathrm{~mm}^{2}$. In the second case, the oval microparticle was extended in the $x$-axis with a length of $0.2 \mathrm{~mm}$ and an equivalent area of $0.094 \mathrm{~mm}^{2}$.

Table 1. Geometries considered for the Transient Thermal and Static analysis.

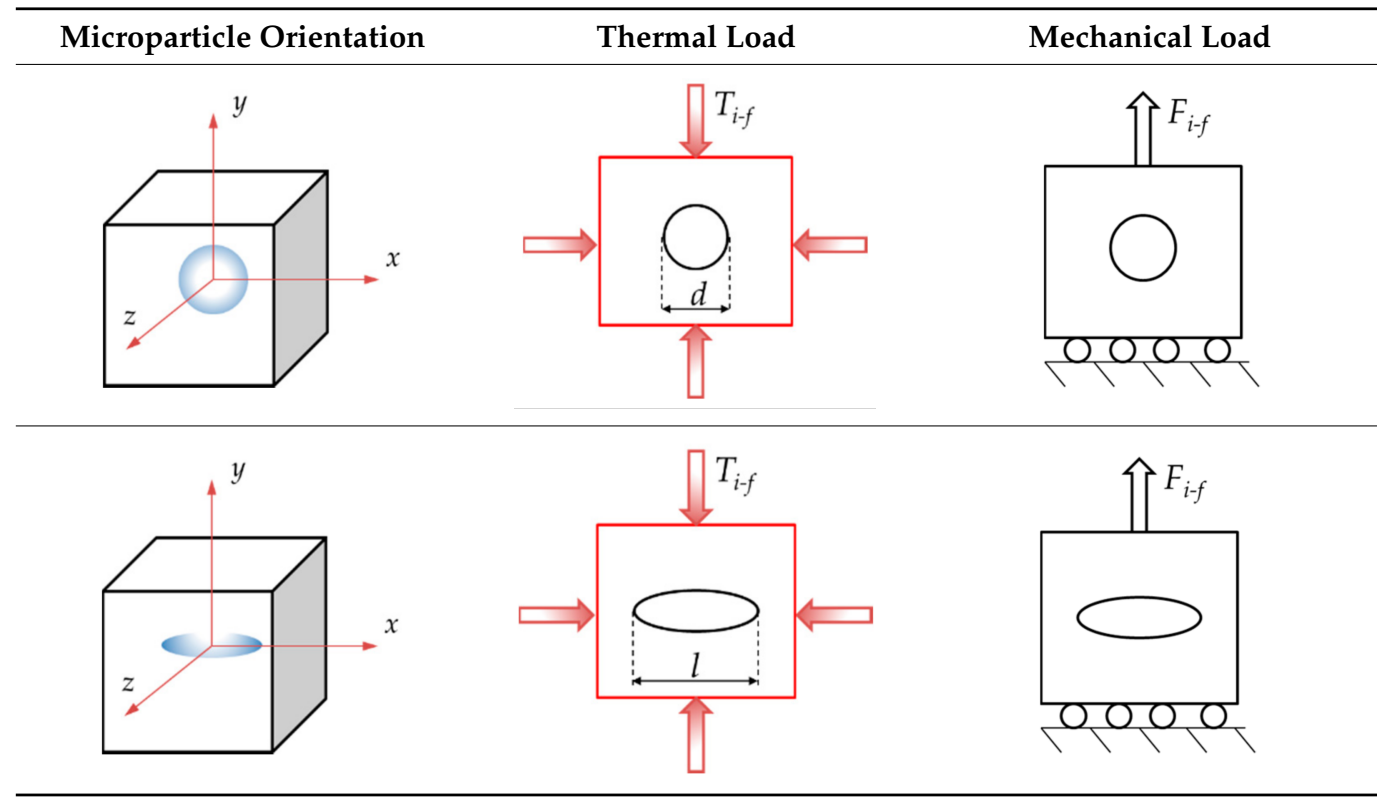

\subsection{Numerical Model Validation}

Figure 2 shows the resulting continuous mesh type of the numerical models obtained with the meshing module of the ANSYS ${ }^{\circledR}$ software (2019-R1-Academic, Ansys Inc., Canonsburg, PA, USA): Figure $2 a$ for the circular microparticle and Figure $2 b$ for the oval microparticle. A series of previous static analyses were carried out to validate both numerical models; these were used to observe the resulting mesh dependence. Figure $2 c, d$ show the relationship between the stress levels for the circle and the oval. In both cases, the 
results stabilized after increasing the mesh by 1000 elements. The final mesh for the circular model consisted of 2500 elements with an average skewness value of 0.03768 and average orthogonality of 0.994 . For the oval model, the resulting mesh was finally composed of 1855 elements with an average skewness value of 0.0527 and average orthogonality of 0.9923. These values correspond to an excellent mesh quality level.

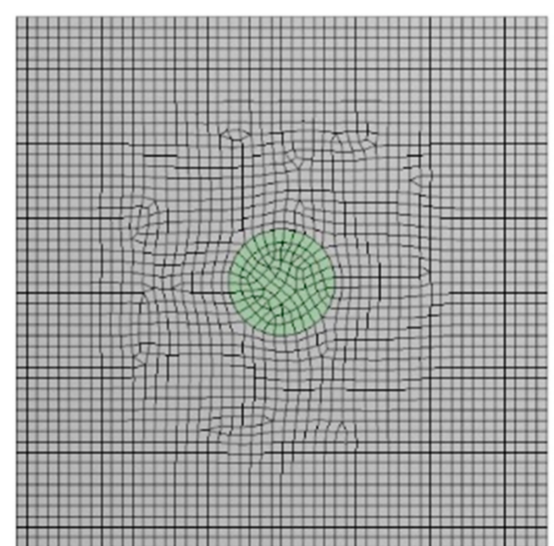

(a)

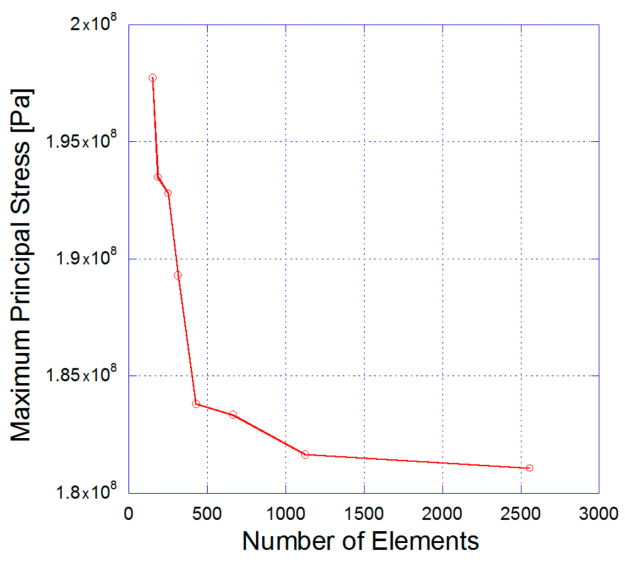

(c)

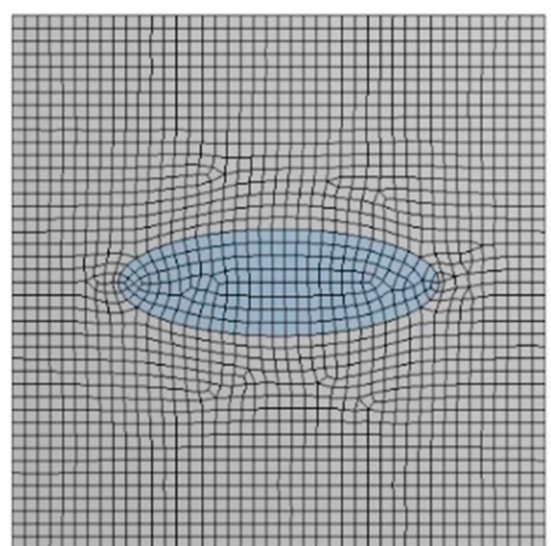

(b)

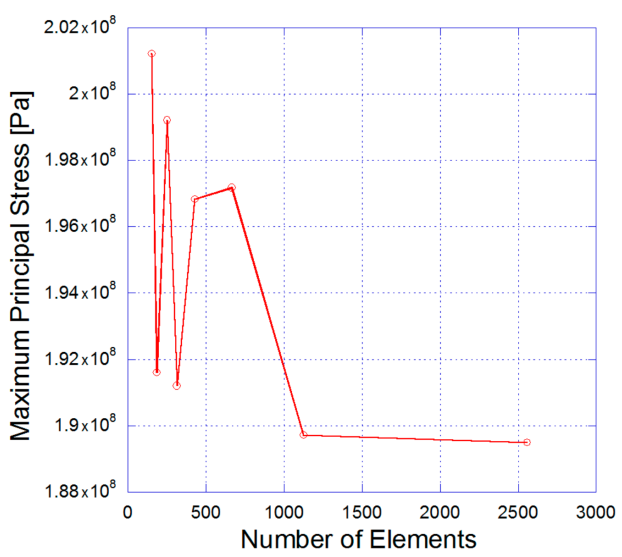

(d)

Figure 2. A resulting mesh of the aluminum matrix with (a) the circular microparticle, (b) the oval microparticle, the maximum principal stress for the number of elements for (c) the circular microparticle, and (d) the oval microparticle.

\subsection{Material Properties}

The purpose of the present simulation was to observe the stress increment during the contraction of the 7075 aluminum [39-41], and according to a predefined cooling sequence in which the thermal and mechanical properties change. These properties are shown in Tables 2 and 3. Table 4 shows the thermal and mechanical properties considered for the $\mathrm{SiO}_{2}$ inclusion [42,43]. These values were proposed and implemented in the simulation as input parameters during the pre-processing set up for the thermal and mechanical fields.

\subsection{Transient Thermal and Static Analysis}

The analysis considers the interaction between two physical fields carried out with the Transient Thermal and Static Structural modules of the ANSYS ${ }^{\circledR}$ 2019R1 software [44]. The analysis is divided into 50 step times; the thermal field is solved first, followed by the mechanical field. The thermal load was applied from step numbers 0 to 29 and the static load from step numbers 30 to 50. The initial conditions of the thermal analysis considered the temperature applied on the external faces of the 2D model of $1 \mathrm{~mm}$ by $1 \mathrm{~mm}$ in length and height; the radius of the microparticle is $0.1 \mathrm{~mm}$. The initial temperature applied on the 
thermal analysis started at $400{ }^{\circ} \mathrm{C}$ and it was reduced every step time to $25^{\circ} \mathrm{C}$. The static analysis started at step number 30 by applying a tension load that increased linearly from 0 to $0.16 \mathrm{~N}$ with increments of $0.001 \mathrm{~N}$. The matrix basement was constrained in the form of a frictionless surface on the horizontal $x$-axis. Figure 3 shows the physical properties of the 7075 aluminum with respect to temperature considered for the simulation; the density is shown in Figure 3a, the coefficient of thermal expansion in Figure 3b, the isotropic thermal conductivity in Figure 3c, the yield stress in Figure 3d, and, finally, Figure 3e shows the modification in Young's modulus.

Table 2. Considered thermal properties of 7075 aluminum with respect to temperature.

\begin{tabular}{ccccc}
\hline Temperature $\left({ }^{\circ} \mathbf{C}\right)$ & Density $\mathbf{( k g \cdot \mathbf { m } ^ { - 3 } )}$ & $\begin{array}{c}\text { Coefficient of Linear } \\
\text { Expansion }\left(\mathbf{C}^{-\mathbf{1})}\right.\end{array}$ & $\begin{array}{c}\text { Thermal Conductivity } \\
\mathbf{( W m}^{-1} \cdot \mathbf{C}^{-\mathbf{1})}\end{array}$ & Specific Heat $\left(\mathbf{J k g}^{-\mathbf{1}} \cdot \mathbf{C}^{-\mathbf{1})}\right.$ \\
\hline 25 & 2811.2 & $2.30 \times 10^{-5}$ & 121.1 & 860.4 \\
100 & 2796.5 & $2.46 \times 10^{-5}$ & 129.4 & 900.7 \\
200 & 2775.6 & $2.67 \times 10^{-5}$ & 138.6 & 943.7 \\
300 & 2753.4 & $2.88 \times 10^{-5}$ & 146.6 & 983.6 \\
400 & 2729.8 & $3.10 \times 10^{-5}$ & 154.1 & 1024.2 \\
500 & 2704.9 & $3.33 \times 10^{-5}$ & 160.5 & 1136.6 \\
\hline
\end{tabular}

Table 3. Considered mechanical properties of 7075 aluminum with respect to temperature.

\begin{tabular}{cccc}
\hline Temperature $\left({ }^{\circ} \mathbf{C}\right)$ & Young Modulus $(\mathrm{GPa})$ & Poisson Ratio & Yield Stress $(\mathbf{M P a})$ \\
\hline 25 & 70.7 & 0.33 & 165.06 \\
100 & 67.8 & 0.33 & 146.13 \\
200 & 63.9 & 0.33 & 102.08 \\
300 & 60.0 & 0.33 & 50.23 \\
400 & 56.1 & 0.33 & 16.91 \\
450 & 52.0 & 0.33 & 8.03 \\
\hline
\end{tabular}

Table 4. Thermal and mechanical properties considered for the $\mathrm{SiO}_{2}$.

\begin{tabular}{cc}
\hline Thermal Properties & Value \\
\hline Thermal conductivity $\left(\mathrm{Wm}^{-1} \mathrm{C}^{-1}\right)$ & 1.5 \\
Specific heat $\left(\mathrm{Jkg}^{-1} \mathrm{C}^{-1}\right)$ & 745 \\
\hline Mechanical properties \\
\hline Young modulus $(\mathrm{GPa})$ & 66.3 \\
Poisson ratio & 0.15 \\
\hline Initial conditions-Heat transfer by convection & \\
\hline Initial temperature $\left({ }^{\circ} \mathrm{C}\right)$ & 400 \\
Co-efficient of the transfer layer $\left(\mathrm{Wm}^{-2} \mathrm{C}^{-1}\right)$ & 15 \\
Environmental temperature $\left({ }^{\circ} \mathrm{C}\right)$ & 25 \\
\hline
\end{tabular}




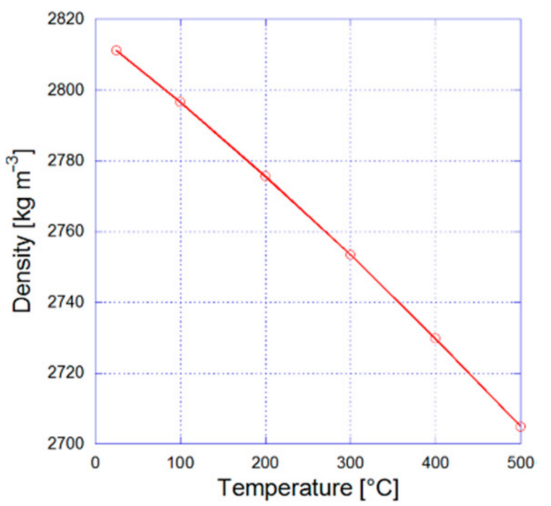

(a)

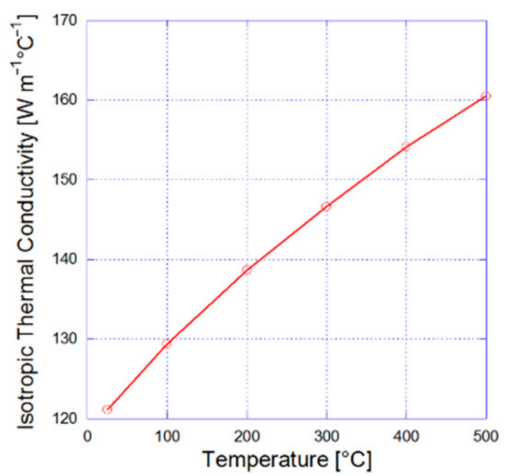

(c)

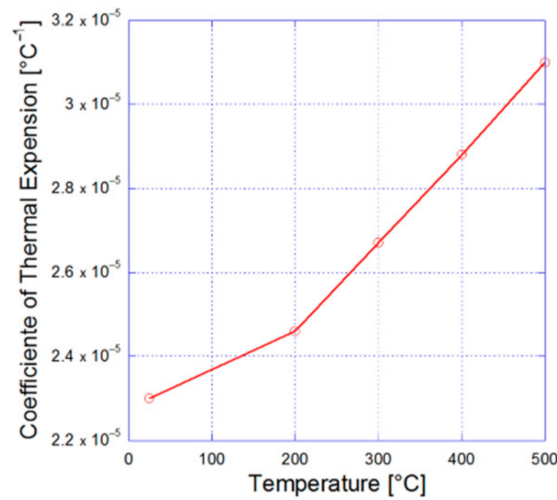

(b)

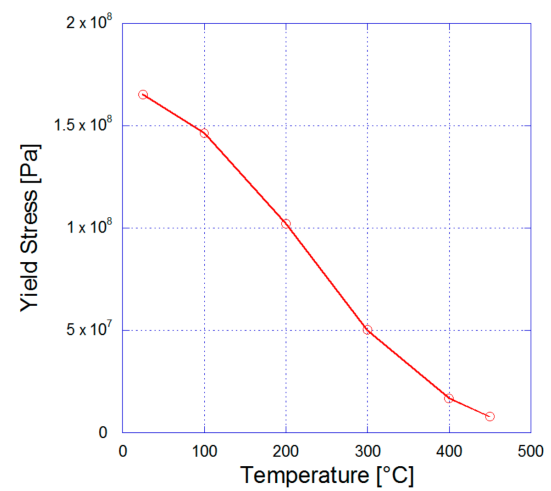

(d)

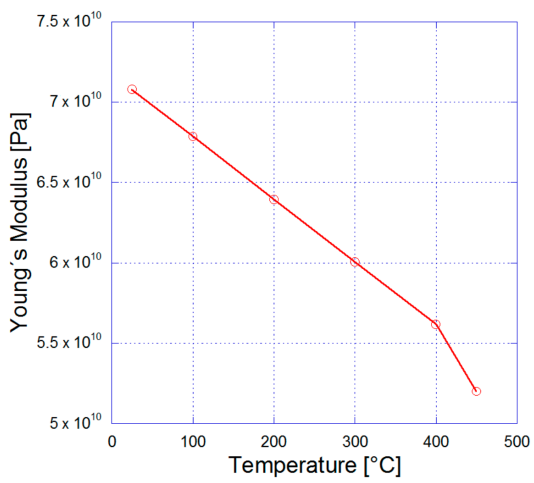

(e)

Figure 3. Variations are considered for every temperature modification with respect to (a) the density, (b) the coefficient of thermal expansion, (c) the isotropic thermal conductivity, (d) the yield stress, and (e) Young's modulus.

\section{Results}

Figure 4 shows the mechanical behavior of the sphere subjected to the Transient Thermal load around the circular $\mathrm{SiO}_{2}$ microparticle. In Figure $4 \mathrm{a}$, the distribution of stresses for step number 10 is observed, and in Figure 4b, step number 20 shows a similar distribution, but with increased magnitude. During the contraction of the material, the microparticle presents a state of compressive stresses. From the boundary, a state of tensile stresses distributed around the microparticle arises. Subsequently, the normal tension load generates the appearance of shear stress planes as shown in Figure 4c, which corresponds to step number 40, and in Figure 4d, which corresponds to step number 50. The maximum 
shear stress planes are observed at approximately $45^{\circ}$. It can be observed that the maximum stress is located at the beginning of the cutting plane.

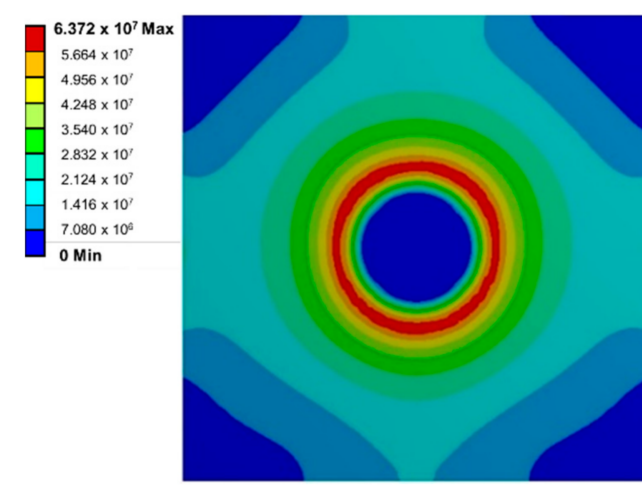

(a)

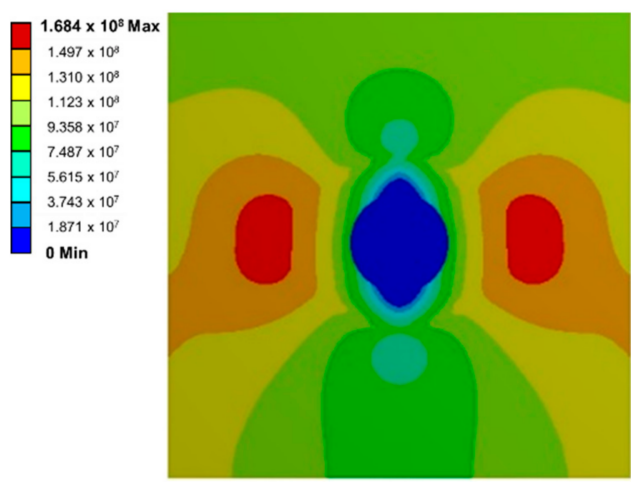

(c)

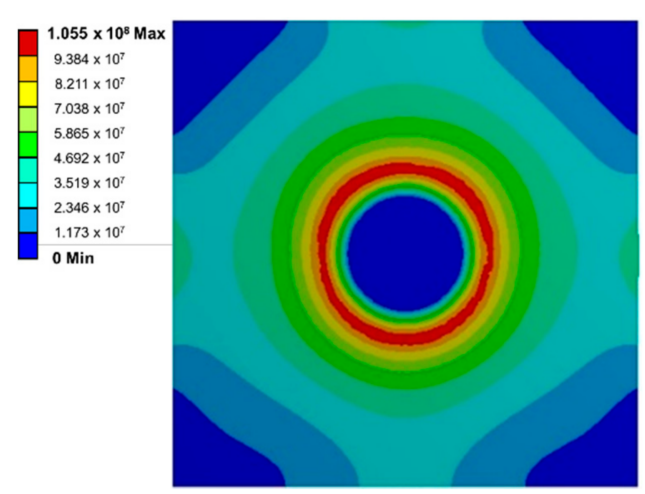

(b)

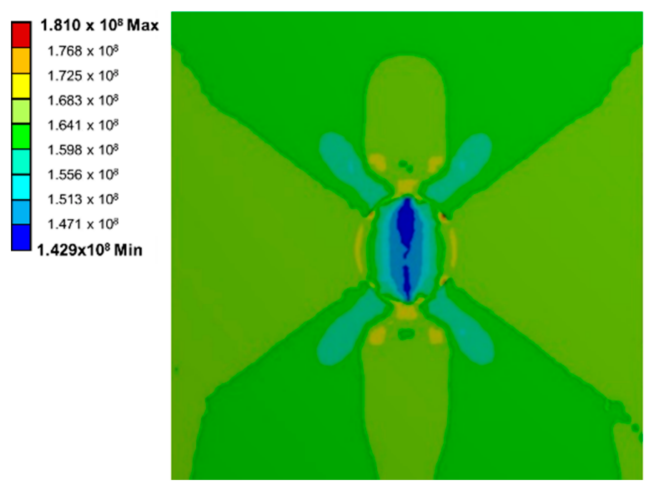

(d)

Figure 4. Stress distribution around the circular $\mathrm{SiO}_{2}$ microparticle for (a) step number 10, (b) step number 20, (c) step number 40, and (d) step number 50 .

Figure 5 shows the mechanical behavior of the oval $\mathrm{SiO}_{2}$ microparticle subjected to the Transient Thermal load. Figure 5a shows the stress distribution for step number 10, and Figure $5 \mathrm{~b}$ for step number 20. Unlike the case of the circular microparticle during the contraction of the material, the stress is concentrated in the vertex of the oval microparticle. Subsequently, it is subjected to a normal tension load and the appearance of shear stress planes are shown in Figure 5c, which corresponds to step number 40, and in Figure 5d, which corresponds to step number 50 . The maximum stress is finally concentrated along the surface of the covertex.

Figure 6 shows the maximum principal stress with respect to the step number, in Figure $6 \mathrm{a}$ for the circular and Figure $6 \mathrm{~b}$ for the oval microparticle.

Figure 7 shows a comparison of stress between both cases with A for the circular and $\mathrm{B}$ for the oval microparticle. The oval microsphere has a more adverse effect on the elastic zone of the material as shown in line B. The oval microsphere increases the ultimate stress after having exceeded the yield stress, which was modified during the Transient Thermal process. The oval geometry increases the maximum stress by 169 MPa for step number 27 . In the same step, the circular microparticle reaches a value of $106 \mathrm{MPa}$. This is the point of greatest difference with a total of $63 \mathrm{MPa}$. It can be observed that as the irregularity of the shape of the microparticle increases, the increment of local stress increases, indicating possible failure appearances. 


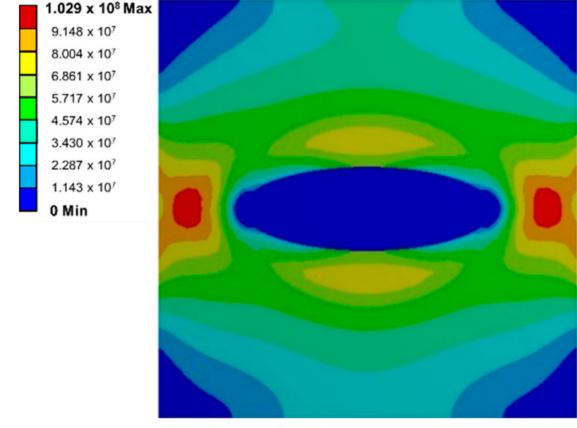

(a)

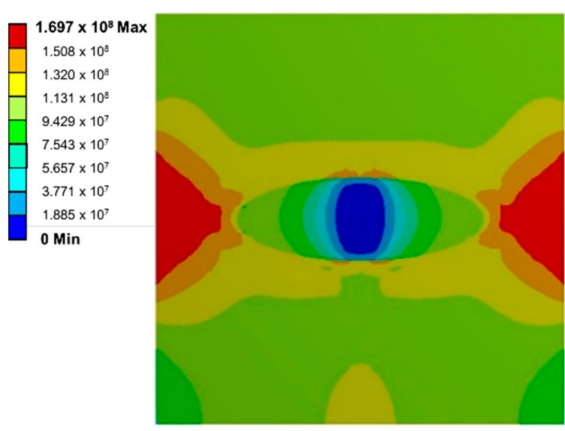

(c)

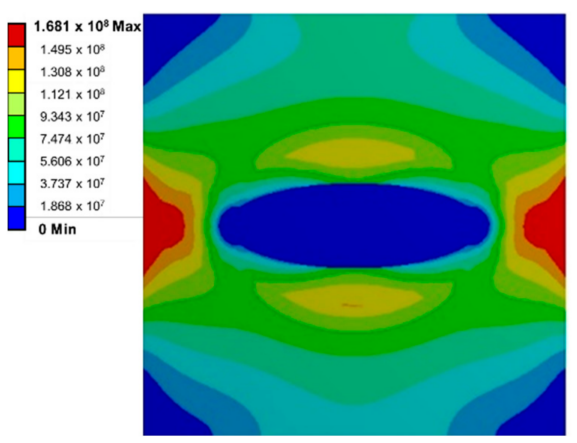

(b)

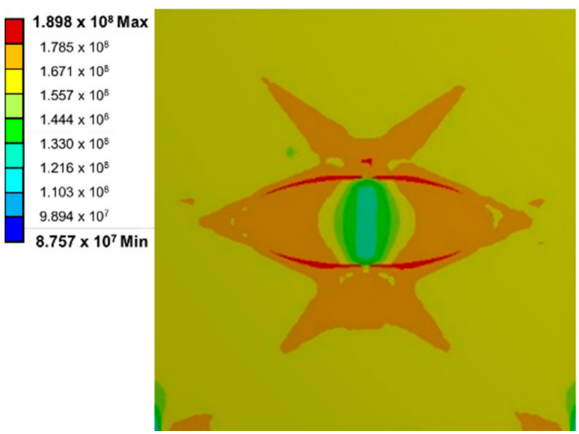

(d)

Figure 5. Stress distribution around the oval $\mathrm{SiO}_{2}$ microparticle for (a) step number 10, (b) step number 20, (c) step number 40, and (d) step number 50.

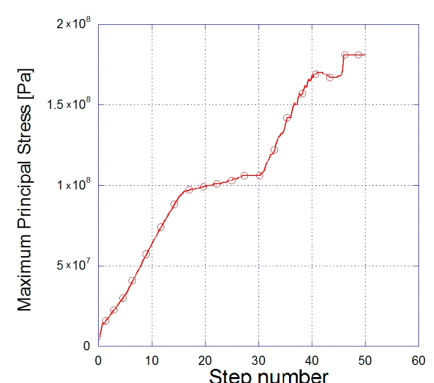

(a)

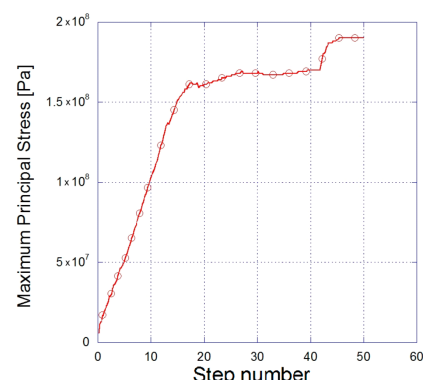

(b)

Figure 6. Maximum principal stress during the transient thermomechanical analysis for (a) the circular and (b) the oval microparticle.

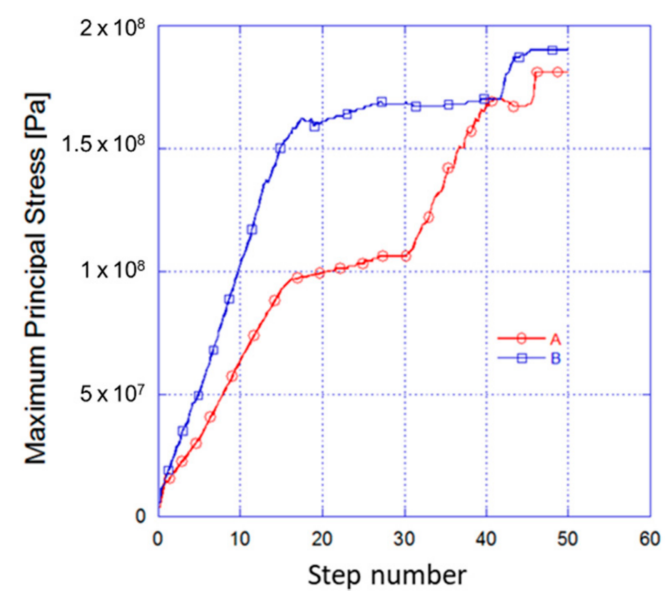

Figure 7. Stress magnitude comparison between A the circular and B the oval microparticle. 


\section{Discussion}

The presence of microparticles immersed in metallic materials can be observed from a dangerous point of view if they are added to the presence of microcracks, inclusions, dislocations, and other types of uncontrolled defects. However, in another sense, they can be beneficial to increase mechanical capabilities. A controlled inclusion of microparticles can be applied to achieve surface improvements under wear conditions using non-metallic materials, as in the case presented here, in which an oxide has been included. The inclusion of this aggregate requires considering a uniformly controlled distribution of the microparticles to achieve the desired distribution of the remaining stresses in their magnitude, direction, and distribution. The proposed model is not a straight postulate, but it is the result of previous analysis related to changes observed during fusion processes. The fundamental characteristic of this model and the method for the analysis is extensive and non-additive, as in the case of analyzing some structurally sensitive properties of metals in the liquid state and their interaction with intermetallic particles arising within the liquid. This means that the entire mass of liquid is part of the phenomena developed in the system.

\section{Conclusions}

The results obtained from the simulation revealed that during the contraction sequence greater compression stress was generated around the microparticle, as expected; but, it is important to notice that the model of the microparticle, in this case, considered idealized conditions. The real shape, size, and distribution of the microparticles must deal with the interaction of grain dynamics, physical characteristics, and dislocations that can arise during thermal treatments. The most important observation found with this simulation was the appearance of non-linearly distributed shear stresses with a higher magnitude around the covertex of the oval shape model. These results must be combined with more complex physical scenarios, in which the proximity of other microparticles can be used to deliberately address the magnitude and direction of remaining stresses and thereby obtain a modified or improved mechanical condition. However, this study allows us to observe how the geometrical irregularities of the microparticles tend to increase the appearance and location of stress concentrations caused by thermal or static loads.

Author Contributions: Conceptualization, P.A.T.-M., methodology and validation, U.S.S.-R., numerical analysis, M.Á.C.-R., literature review, L.A.F.-H., validation, R.R.-B. and E.A.M.-C. All authors have read and agreed to the published version of the manuscript.

Funding: This research was funded by the Instituto Politécnico Nacional-Secretaría de Investigación y Posgrado through grants numbers 20190282, 201958000, and 20180685 of the SIP projects and the Tecnológico de Estudios Superiores de Coacalco.

Data Availability Statement: Data sharing not applicable this article.

Acknowledgments: The authors acknowledge the Instituto Politécnico Nacional. The authors also acknowledge the Consejo Nacional de Ciencia y Tecnología (CONACYT).

Conflicts of Interest: The authors declare no conflict of interest. The funders had no role in the design of the study; in the collection, analyses, or interpretation of data; in the writing of the manuscript; or in the decision to publish the results.

\section{References}

1. Frenkel, J. Zur Theorie der Elastizitätsgrenze und der Festigkeit kristallinischer Körper. Z. Für Phys. 1926, 37, 572-609. [CrossRef]

2. Pustovoit, V.N.; Churyukin, Y.N.; Blinovskii, V.A. Reasons for the Formation of an Abnormal Structure of Pearlite in Cooling a Powder Steel Produced on the Basis of UI0 Steel. Poroshkovaya Metall. 1991, 7, 44-48.

3. Bhoi, N.K.; Singh, H.; Pratap, S. Developments in the aluminum metal matrix composites reinforced by micro/nano particles-A review. J. Compos. Mater. 2020, 54, 813-833. [CrossRef]

4. Repeto, D.; Fernández-Vidal, S.R.; Mayuet, P.F.; Salguero, J.; Batista, M. On the Machinability of an Al-63\%SiC Metal Matrix Composite. Materials 2020, 13, 1186. [CrossRef] [PubMed]

5. Kulisz, M.; Zagórski, I.; Korpysa, J. The Effect of Abrasive Waterjet Machining Parameters on the Condition of Al-Si Alloy. Materials 2020, 13, 3122. [CrossRef] [PubMed] 
6. Nakae, $\mathrm{H}$;; $\mathrm{Wu}, \mathrm{S}$. Engulfment of $\mathrm{Al}_{2} \mathrm{O}_{3}$ particles during solidification of aluminum matrix composites. Mater. Sci. Eng. A 1998, 25, 232-238. [CrossRef]

7. Wang, B.; Dong, F.; Wang, Z.; RDK, M.; Wang, G. Microstructure and mechanical properties of Nb-B bearing low carbon steel plate: Ultrafast cooling versus accelerated cooling. J. Wuhan Univ. Technol. Mater. Sci. Ed. 2017, 32, 619-624. [CrossRef]

8. Liu, X.; Lou, Y.; Yu, B.; Su, G.; Li, C.; Guo, X.; Li, B.; Shui, G. Directional solidification casting technology of heavy-duty gas turbine blade with liquid metal cooling (LMC) process. China Foundry 2019, 16, 23-30. [CrossRef]

9. Brundidge, C.; Miller, J.; Pollock, T. Development of Dendritic Structure in the Liquid-Metal-Cooled, Directional-Solidification Process. Metall. Mater Trans A 2011, 42, 2723-2732. [CrossRef]

10. Zhaojin, W.; Deping, H. Changes in porosity of foamed Al during solidification. Chin. Sci. Bull. 2000, 45, 1667-1672.

11. Song, Z.; He, D. Effects of viscosity on pore structure in foaming process of molten aluminum. Chin. J. Mater. Res. 1997, 11, 275-279.

12. Yang, D.; He, D. Porosity of porous Al alloys. Sci. China Ser. B Chem. 2001, 44, 411-418. [CrossRef]

13. Ryzhikov, A.A.; Solomko, V.P.; Volkov, A.E.; Moiseenko, R.G. Reasons for the Formation of Defects in the Fractures of Steels. Met. Sci. Heat Treat. 1981, 23, 731-735. [CrossRef]

14. Brundidge, C.L.; Vandrasek, D.; Wang, B.; Pollock, T.M. Structure Refinement by a Liquid Metal Cooling Solidification Process for Single-Crystal Nickel-Base Superalloys. Metall. Mater. Trans. A 2012, 43, 965. [CrossRef]

15. Kermanpur, A.; Rappaz, M.; Varahram, N.; Davami, P. Thermal and grain-structure simulation in a land-based turbine blade directionally solidified with the liquid metal cooling process. Met. Mater. Trans. B 2000, 31, 1293-1304. [CrossRef]

16. Cao, X.; Campbell, J. Oxide Inclusion Defects in Al-Si-Mg Cast Alloys. Can. Metall. Q. 2005, 44, 435-448. [CrossRef]

17. Osoba, L.; Owolabi, O.B.; Talabi, S.I.; Adeosun, S. Review on Oxide Formation and Aluminum Recovery Mechanism during Secondary Smelting. J. Cast. Mater. Eng. 2018, 2, 45-51. [CrossRef]

18. Cao, X.; Campbell, J. A critical review of techniques for the removal of oxide. In Proceedings of the 2nd International Aluminum Casting Technology Symposium, Columbus, OH, USA, 7-9 October 2002; pp. 135-146.

19. Lvi, X.; Zhang, L. Purification of aluminum through gas and powder fluxing: Part i. mathematical models. Can. Metall. Q. 2009, 48, 369-377. [CrossRef]

20. Wynnyckyj, J.R.; Pidgeon, L.M. Investigations on the system consisting of calcium oxide, magnesium oxide and alloys of aluminum-silicon-iron. Can. Metall. Q. 1971, 10, 105-113. [CrossRef]

21. Bihuniak, P.P.; Condrate, R.A. Structures, spectra and related properties of group IVB-doped vitreous silica. J. Non-Cryst. Solids 1981, 44, 331-343. [CrossRef]

22. Wu, T.; He, S.P.; Zhu, L.L.; Wang, Q. Study on reaction performances and applications of mold flux for high-aluminum steel. Mater. Trans. 2016, 57, 58-63. [CrossRef]

23. Özşahin, E.; Tolun, S. On the comparison of the ballistic response of coated aluminum plates. Mater. Des. 2010, $31,3188-3193$. [CrossRef]

24. Atraszkiewicz, R.; Makówka, M.; Kołodziejczyk, Ł.; Januszewicz, B.; Sucharkiewicz, J. Frictional Behaviour of Composite Anodized Layers on Aluminium Alloys. Materials 2020, 13, 3747. [CrossRef] [PubMed]

25. Tian, W.; Li, Z.; Kang, H.; Cheng, F.; Chen, F.; Pang, G. Passive Film Properties of Bimodal Grain Size AA7075 Aluminium Alloy Prepared by Spark Plasma Sintering. Materials 2020, 13, 3236. [CrossRef]

26. Kurzawa, A.; Pyka, D.; Jamroziak, K.; Bajkowski, M.; Bocian, M.; Magier, M.; Koch, J. Assessment of the Impact Resistance of a Composite Material with EN AW-7075 Matrix Reinforced with $\alpha-\mathrm{Al}_{2} \mathrm{O}_{3}$ Particles Using a $7.62 \times 39$ mm Projectile. Materials 2020, 13, 769. [CrossRef]

27. Ponnusamy, P.; Rahman Rashid, R.A.; Masood, S.H.; Ruan, D.; Palanisamy, S. Mechanical Properties of SLM-Printed Aluminium Alloys: A Review. Materials 2020, 13, 4301. [CrossRef]

28. Kannan, S.; Pervaiz, S.; Alhourani, A.; Klassen, R.J.; Selvam, R.; Haghshenas, M. On the Role of Hollow Aluminium Oxide Microballoons during Machining of AZ31 Magnesium Syntactic Foam. Materials 2020, 13, 3534. [CrossRef]

29. Fedorova, N.; Ottinger, B.; Jovicic, V.; Zbogar-Rasic, A.; Delgado, A.; Virtanen, S. Static Wettability of Differently Mechanically Treated and Amphiphobic-Coated Aluminium Surfaces. Materials 2020, 13, 2240. [CrossRef]

30. Lloyd, D. Particle reinforced aluminium and magnesium matrix composites. Int. Mater. Rev. 1994, 39, 1-23. [CrossRef]

31. Kumar, S.; Pandey, R.; Panwar, R.; Pandey, O. Effect of Particle Size on Wear of Particulate Reinforced Aluminum Alloy Composites at Elevated Temperatures. J. Mater. Eng. Perform 2013, 22, 3550-3560. [CrossRef]

32. Alpas, A.; Zhang, J. Effect of SiC particulate reinforcement on the dry sliding wear of aluminium-silicon alloys (A356). Wear 1992, 155, 83-104. [CrossRef]

33. Galek, T.; Łączek, A.; Łysiak, K. Study of Nonmetallic Inclusions in Aluminum-Silicon Alloys. Adv. Manuf. Sci. Technol. 2020, 44, 28-31. [CrossRef]

34. Kilaas, R.; Radmilovic, V. Structure determination and structure refinement of $\mathrm{Al} 2 \mathrm{CuMg}$ precipitates by quantitative highresolution electron microscopy. Ultramicroscopy 2001, 88, 63-72. [CrossRef]

35. Tanimoto, Y.; Nemoto, K. Development of $\mathrm{Al}_{2} \mathrm{O}_{3}$ fiber-reinforced $\mathrm{Al}_{2} \mathrm{O}_{3}$-based ceramics. Dent. Mater. J. 2004, 23, 297-304. [CrossRef] [PubMed]

36. Rhead, G.; Mykura, H. Thermal etching of silver. Acta Metall. 1962, 10, 578-579. [CrossRef]

37. Zhu, Y.H. General Rule of Phase Decomposition in Zn-Al Based Alloys (II). Mater. Trans. 2004, 45, 3083-3097. [CrossRef] 
38. Tiller, W.A.; Takahashi, T. The electrostatic contribution in heterogeneous nucleation theory: Pure liquids. Acta Metall. 1969, 17, 483-496. [CrossRef]

39. Florando, J.N.; Margraf, J.D.; Reus, J.F.; Anderson, A.T.; McCallen, R.C.; LeBlanc, M.M.; Stanley, J.R.; Rubenchik, A.M.; Wu, S.S.; Lowdermilk, W.H. Modeling the effect of laser heating on the strength and failure of 7075-T6 aluminum. Mater. Sci. Eng. A 2015, 640, 402-407. [CrossRef]

40. Jeanmart, P. Finite element calculation and measurement thermal stresses in quenched plates of high-strength 7075 aluminium alloy. Mater. Sci. Technol. 1985, 1, 765-769. [CrossRef]

41. Lu, J.; Song, Y.; Hua, L.; Zheng, K.; Dai, D. Thermal deformation behavior and processing maps of 7075. J. Alloys Compd. 2018, 767, 856-869. [CrossRef]

42. Chen, Z.; Zhang, Y.B.; He, S.P.; Li, Z.R.; Wang, Q. Reaction performances of mold slags with different $\mathrm{SiO}_{2}$ contents for 321 stainless steel. Can. Metall. Q. 2019, 58, 464-470. [CrossRef]

43. AZoM. SilicaSilicon Dioxide $\left(\mathrm{SiO}_{2}\right)$. AZO Materials. 2001. Available online: https://www.azom.com/article.aspx?ArticleID=1114 (accessed on 25 May 2020).

44. ANSYS, Inc. Ansys ${ }^{\circledR}$ Academic, Release 19.1, Help System, Coupled Field Analysis Guide. Available online: https://www.ansys. $\mathrm{com} /$ academic/terms-and-conditions (accessed on 25 May 2020). 